\title{
Final Visual Acuity Results in the Early Treatment for Retinopathy of Prematurity Study
}

\author{
The Early Treatment for Retinopathy of Prematurity Cooperative Group ${ }^{*}$
}

\begin{abstract}
Objective-To compare visual acuity at 6 years of age in eyes that received early treatment for high-risk prethreshold retinopathy of prematurity (ROP) with conventionally-managed eyes.

Methods-Infants with symmetrical, high-risk prethreshold ROP $(\mathrm{N}=317)$ had one eye randomized to earlier treatment at high-risk prethreshold disease and the other eye managed conventionally, treated if ROP progressed to threshold severity. For asymmetric cases $(\mathrm{N}=84)$, the high-risk prethreshold eye was randomized to either early treatment or conventional management.
\end{abstract}

Main Outcome Measures-ETDRS visual acuity measured at 6 years of age by masked testers. Retinal structure was assessed as a secondary outcome.

Results-Analysis of all subjects with high-risk prethreshold ROP showed no statistically significant benefit for early treatment (24.6\% v. $29.0 \%$ unfavorable outcome, $\mathrm{P}=0.15$ ). Analysis of 6-year visual acuity results according to the Type 1 and 2 clinical algorithm showed a benefit for Type 1 eyes $(25.1 \%$ v. $32.8 \%, \mathrm{P}=0.02)$ treated early, but not Type 2 eyes ( $23.6 \%$ v. $19.4 \%$, $\mathrm{P}=0.37)$. Early treated eyes showed a significantly better structural outcome compared with conventionally managed eyes $(8.9 \%$ v. $15.2 \%$ unfavorable outcome, $\mathrm{P}<0.001)$, with no greater risk of ocular complications.

Conclusion-Early treatment for Type 1 high-risk prethreshold eyes improved visual acuity outcomes at 6 years of age. Early treatment for Type 2 high-risk prethreshold eyes did not.

Application to Clinical Practice-Type 1 eyes, not Type 2 eyes should be treated early. These results are particularly important considering that $52 \%$ of Type 2 high-risk prethreshold eyes underwent regression of ROP without requiring treatment.

\section{Introduction}

The Multicenter Trial of Cryotherapy for Retinopathy of Prematurity Study (CRYO-ROP) evaluated the effectiveness of peripheral retinal ablation at threshold disease (Figure 1) for the treatment of retinopathy of prematurity (ROP), ${ }^{1,2}$ using the international classification for retinopathy of prematurity (ICROP). ${ }^{3}$ The CRYO-ROP Study defined prethreshold ROP (Figure 1) to help identify infants' eyes at risk for progression to threshold. Cryotherapy reduced the rate of adverse outcome in threshold ROP by approximately $50 \%$, but many important questions remained about the disease and its treatment. ${ }^{4}$

The Early Treatment for Retinopathy of Prematurity (ETROP) Study was designed to test the hypothesis that early treatment in high-risk prethreshold eyes would further improve 
Bedard, MD; Renato Casabar, MD; Antonio Capone, MD; Edward O'Malley, MD; Rajesh Rao, MD; John Roarty, MD; Michael

Trese, MD; George Williams, MD.

Minneapolis Center (Minneapolis, MN). Fairview University Medical Center, Children's Health Care, Minneapolis, Hennepin County Medical Center. Principal Investigator: C. Gail Summers, MD; Study Center Coordinators: Sally Cook, BA; Ann Holleschau,

BA; Molly Maxwell, RN; Coinvestigators: Stephen P. Christiansen, MD; David Brasel, MD.

St. Louis Center (St. Louis, MO). Cardinal Glennon Children's Medical Center, St. Mary's Health Center. Principal Investigator:

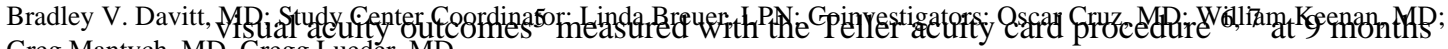
Greg Mantych, MD, Gregg Lueder, MD.

North Carolina Center (Durham, NC). Duke University Medical Center. Principal Investigator: Sharon Freedman, MD; Coprincipal Investigator: David Wallace, MD, MPH; Study Center Coordinators: Lori Hutchins Parkman, RN; Sarah K. Jones; Coinvestigators: Laura Enyedi, MD; Ricki F. Goldstein, MD.

Buffalo Center (Buffalo, NY). Women's and Children's Hospital of Buffalo, Sisters of Charity Hospital. Principal Investigator: James D. Reynolds, MD; Study Center Coordinator: Kristine Ziemann, RN, BSN; Coinvestigators: George P. Albert, MD; Steven Awner, MD; Rita Ryan, MD.

Long Island/Westchester Center (New York). Stony Brook University Hospital, Westchester Medical Center. Principal Investigator: Pamela Ann Weber, MD; Co-principal Investigator: Marc Horowitz, MD; Study Center Coordinators: Cherylene Behrendt; Adriann Combs; Natalie Dweck, RN; Coinvestigators: Richard Koty, MD; Edmund LaGamma, MD; Maury Marmor, MD. New York Center (New York, NY). New York Presbyterian Hospital, Columbia Campus, New York Presbyterian Hospital, Cornell Campus. Principal Investigator: John Flynn, MD; Study Center Coordinator: Osode Coki, RNC, BSN; Coinvestigators: Michael Chiang, MD, MPH; Steven Kane, MD; Alfred Krauss, MD; Thomas C. Lee, MD, PhD; Robert F. Lopez, MD; Richard Polin, MD. Rochester/Syracuse Center (New York). University of Rochester Medical Center, Crouse-Irving Memorial Hospital. Principal Investigator: Dale L. Phelps, MD; Study Center Coordinators: Cassandra Horihan, MS; Jane Phillips; Coinvestigators: Gary Markowitz, MD; Walter Merriam, MD; Leon-Paul Noel, MD; Donald Tingley, MD; Matthew Gearinger, MD.

Columbus Center (Columbus, Ohio). Nationwide Children's Hospital. Principal Investigator: Gary L. Rogers, MD; Co-principal Investigator: Don Bremer, MD; Study Center Coordinators: Rae Fellows, MEd; Sharon Klamfoth, LPN; Coinvestigators: Brian Arthur, MD; Cybil Bean Cassady, MD; Richard Golden, MD; Mary Lou McGregor, MD.

Oklahoma City Center (Oklahoma City, OK). University of Oklahoma Health Sciences Center; Dean A. McGee Eye Institute. Principal Investigator: R. Michael Siatkowski, MD; Study Center Coordinators: Cheryl Harris, COA; Vanessa Yazdanipanah; Coinvestigators: Reagan H. Bradford, MD; Robert E. Leonard, MD; Mary Anne McCaffree, MD.

Portland Center (Portland, OR). Doernbecher Children's Hospital at Oregon Health and Science University. Principal Investigator: David T. Wheeler, MD; Study Center Coordinator: Nancy Dolphin, RN; Coinvestigators: Earl A. Palmer, MD; Ann Stout, MD; Brian Nichols, MD; David Epley, MD.

Philadelphia Center (Philadelphia, PA). The Children's Hospital of Philadelphia, The Hospital of the University of Pennsylvania, Pennsylvania Hospital. Principal Investigator: Graham E. Quinn, MD, MSCE; Study Center Coordinators: Jamie G. Koh, RN, MSN, CCRC; Marianne Letterio, RN, BSN; Coinvestigators: Soraya Abbasi, MD; Jane C. Edmond, MD; Brian J. Forbes, MD, PhD; Albert M. Maguire, MD; Monte D. Mills, MD; Eric A. Pierce, MD; Terri L. Young, MD; Stephanie Davidson, MD.

Pittsburgh Center (Pittsburgh, PA). Magee-Women's Hospital. Principal Investigator: Kenneth Cheng, MD; Study Center Coordinators: Janice Kelchner-Cheng, RN; Judith Jones, RNC, BSN; Coinvestigators: Robert Bergren, MD; Bernard Doft, MD; Louis Lobes, MD; Karl Olsen, MD.

Charleston Center (Charleston, SC). Medical University of South Carolina. Principal Investigator: Richard A. Saunders, MD; Coprincipal Investigator: Dilip Purohit, MD; Study Center Coordinator: Linda Stevens, RN; Vision Tester: Kimberly Lenhart. Houston Center (Houston, TX). Baylor College of Medicine, Texas Children's Hospital, Texas Woman's Hospital, Ben Taub General Hospital. Principal Investigator: David K. Coats, MD; Study Center Coordinators: Michele L. Parker, COA; Maria Castanes, MPH; Alison Brown; Coinvestigators: Jane Edmond, MD; Joseph Garcia-Prats, MD; Eric Holz, MD; W. Scott Jarriel, MD; Karen Johnson, MD; George Mandy, MD; Evelyn A. Paysee, MD; A. Melinda Rainey, MD; Paul G. Steinkuller, MD; Kimberly G. Yen, MD;.

San Antonio Center (San Antonio, TX). University of Texas Health Science Center, University Hospital, Christus Santa Rosa Children's Hospital. Principal Investigator: John P. Stokes, MD; Study Center Coordinator: Yolanda Trigo, COT; Coinvestigators: Alice K. Gong, MD; W.A.J. van Heuven, MD.

Salt Lake City Center (Salt Lake City, UT). University of Utah Health Science Center, Primary Children's Medical Center. Principal Investigator: Robert Hoffman, MD; Study Center Coordinator: Susan Bracken, RN; Deborah Y. Harrison, MS; Coinvestigators: Paul Bernstein, MD; Jerald King, MD; Michael Teske, MD.

National Eye Institute, Bethesda, MD. Program Officer: Maryann Redford, DDS, MPH (June, 2001-Present); Richard L. Mowery, PhD (October, 2000-May, 2001); Donald F. Everett, MA (September, 1999-September, 2000).

Study Headquarters: Smith-Kettlewell Eye Research Institute, San Francisco, CA. Principal Investigator: William V. Good, MD; Project Coordinator: Michelle Quintos, BA.

Coordinating Center: School of Public Health, Coordinating Center for Clinical Trials, University of Texas Health Science Center, Houston, TX. Principal Investigator: Robert J. Hardy, PhD; Coinvestigators: Betty Tung, MS, Dejian Lai, PhD; Coordinating Center Staff: Gordon Tsai, MS.

Vision Testing Center: University of Arizona, College of Medicine, Tucson, AZ. Principal Investigator: Velma Dobson, PhD; Vision Testers: Deborah D. Hargadon, Jeffrey Wood; Coinvestigators: Graham E. Quinn, MD, Erin M. Harvey, PhD.

Data and Safety Monitoring Committee: Chair: John Connett, PhD; Members: Edward F. Donovan, MD; Argye Hillis, PhD; Jonathan M. Holmes, MD; Joseph M. Miller, MD; Carol R. Taylor, RN, CSFN, PhD; Ex-officio Members: William V. Good, MD; Robert J. Hardy, PhD; Maryann Redford, DDS, MPH.

Executive Committee: Permanent Members: Chair: William V. Good, MD; Robert J. Hardy, PhD; Velma Dobson, PhD; Earl A. Palmer, MD; Dale L. Phelps, MD; Maryann Redford, DDS, MPH.

Executive Committee: Elected Members: W.A.J. van Heuven, MD (2000-2001; 2004-2007); Charles Barr, MD (2001-2002); Michael Gaynon, MD (2002-2003); Michael Shapiro, MD (2003-2004); David Wallace, MD (2007-2008); Bradley V. Davitt, MD (2008-Present); Rae Fellows, MEd (2000-2001; 2006-Present); Judith Jones, RNC, BSN (2001-2002); Kristi Cumming, MSN (2002-2003); Deborah S. Neff, LPN (2003-2004); Jennifer A. Shepard, NNP (2004-2006); Nancy Dolphin, RN (2006-Present). Editorial Committee: Chair: William V. Good, MD; Robert J. Hardy, PhD; Velma Dobson, PhD; Earl A. Palmer, MD; Dale L. Phelps, MD; Michelle Quintos, BA; Betty Tung, MS. 
corrected age. ${ }^{8}$ High risk was determined by an equation derived from analyses of CRYOROP data that took into account a number of risk factors. ${ }^{9}$ If an infant with prethreshold ROP had a risk for progression to an unfavorable outcome equal to or greater than $15 \%$, randomization was offered, with one eye treated early and the other followed and managed conventionally (RM-ROP2). ${ }^{9}$ Conventional management consisted of treatment at threshold (Figure 1) or observation until the ROP regressed without needing treatment. In infants with only one eye eligible, the high-risk prethreshold eye was randomized to early treatment or conventional management.

The ETROP Study showed a benefit for 9-month grating acuity for eyes with high-risk prethreshold ROP treated with peripheral retinal ablation. ${ }^{8}$ A retinal structural outcome benefit was also noted for eyes receiving early treatment. This structural benefit of early treatment was shown to persist to at least 2 years of age. ${ }^{10}$

Recognizing that use of the risk model algorithm to determine indications for treatment might not always be practical in an intensive care nursery setting, the ETROP Cooperative Group also analyzed results based only on the ocular changes of ROP. Importantly, these analyses resulted in a clinical algorithm wherein Type 1 and Type 2 prethreshold disease emerged as indications for treatment, or cautious observation, respectively. Type 1 eyes are those with plus disease in either Zone I or Zone II, or Zone I stage 3 disease. ${ }^{8}$ Type 2 eyes are all other eyes with prethreshold disease, whether high-risk or not (Figure 1). Plus disease was defined as dilation and tortuosity of posterior retinal vessels in at least 2 quadrants, as compared with a standard published picture (Figure 2). Clinical use of the Type 1 and Type 2 categories may decrease treatment of eyes that would undergo regression of ROP without requiring retinal ablation.

Type 1 prethreshold ROP is not identical to high-risk prethreshold ROP, nor is Type 2 synonymous with low-risk prethreshold ROP. These categories, Types 1 and 2, were developed, based on all prethreshold eyes (not only high-risk prethreshold eyes) in the ETROP Study to learn whether anatomical features defined in ICROP could be used by practicing ophthalmologists at the cribside to determine whether an infant's eye or eyes would benefit from treatment. The ETROP Study recommended that Type 1 eyes should be treated promptly, while Type 2 eyes could be watched carefully, and treated if the ROP progressed to Type 1 . The difference between Type 1 and Type 2 versus low risk and high risk pre-threshold eyes is developed fully in a previous publication. ${ }^{8}$

Many questions about the effect of early treatment of eyes were raised after publication of the ETROP 9-month visual acuity outcomes paper. Would the benefit to visual acuity for early treated eyes seen at 9 months persist to age 6 years, and what would be the long-term effect of extensive retinal ablation on visual field extent? Would Type 1 and Type 2 diagnoses remain useful? This article presents the visual acuity and structural findings at 6 years of age for children who were randomized into the ETROP study in the perinatal period. 


\section{Methods}

Study protocols were approved by the review boards of all participating institutions, and parents provided written informed consent for participation in the extended follow-up study to allow vision measurements on a yearly basis through 6 years of age.

A total of 401 infants were randomized between October 1, 2000 and September 30, 2002. Three hundred seventy of these children survived until 6 years of age (Figure 3A). Details of the design of the ETROP Study, and of the model used to calculate whether an infant was at high or low risk, have been previously published..${ }^{9}{ }^{11}$ Randomized infants had either symmetrical, high-risk prethreshold disease, in which case one eye was randomized to early treatment and the other to conventional management, or they had one eye with high-risk prethreshold disease, which was randomized to either early treatment or conventional management.

\section{Visual acuity assessment}

Recognition (letter) visual acuity was assessed with the Early Treatment Diabetic Retinopathy Study (ETDRS) charts ${ }^{12}$ (Precision Vision, Inc., LaSalle, IL) in all children whose developmental skills allowed the measurement. Children were excluded from the visual acuity examination if both a certified examiner and parent agreed that both eyes had only LP or worse vision, and the child had bilateral retinal detachments, phthisis bulbi, or bilateral enucleations.

Testing was conducted by a masked, traveling tester who was unaware of the child's treatment assignment. The testing location was a comfortable, quiet room, and luminance of the ETDRS chart was at least $10 \mathrm{~cd} / \mathrm{m}^{2}$. All children underwent cycloplegic refraction within 3 months of the final 6-year acuity assessment. Glasses were required for myopia in an eye $\geq$ 1.00 diopter (D); hyperopia $\geq 4.00 \mathrm{D}$; or astigmatism $\geq 1.50 \mathrm{D}$. In the case of amblyopia as judged by the examining ophthalmologist, glasses were required for anisometropia $\geq 1.50 \mathrm{D}$ spherical equivalent or cylinder. Cycloplegic refraction was performed immediately after visual acuity testing. If it was determined that the child's refraction was not corrected to within the above limits, the acuity test was repeated with the proper prescription. Because each child underwent yearly eye examinations as part of the study, amblyopia, strabismus, and refractive errors were managed prior to the 6-year examination.

The procedure used for assessment of recognition acuity consisted of three steps: training, screening, and testing. The training and screening steps were conducted binocularly, and the testing step was conducted monocularly, with the right eye tested first. In the training step, the child was taught about the test by parents, who were sent sample acuity letters by mail preceding the final visit. The child was also given instructions by the tester at the time of the acuity test. Next, the tester screened the child for the ability to take the test by showing large, individual copies of the 10 letters on the test at a distance of approximately $1 \mathrm{~m}$, to determine whether the child could identify each letter by naming or by matching to letters on a lap card. A child continued to the acuity testing step only if he or she correctly identified or matched 9 out of 10 consecutive letters. If a child could not name or match the letters due to developmental or cognitive reasons, then testing with an HOTV chart was attempted. 
HOTV testing was not performed on all children. Those who could only perform the HOTV task or whose score on developmental assessment indicated moderately delayed cognitive status were scheduled for a repeat visual acuity test 6-12 months later.

The visual acuity test was performed as follows. The child was seated comfortably, wearing glasses or trial frames if needed to correct refractive error. The left eye was covered with an adhesive eye patch. Test distance was 4 meters, but was reduced to $1 \mathrm{~m}$ or to $0.5 \mathrm{~m}$, if needed to permit letter identification in an eye with poor vision. The child read from the top line down, until he or she missed 3 letters on a line. The line above this was scored as the visual acuity threshold for that eye, with appropriate adjustment for the chart distance. The tester moved the patch to the right eye, and using a different ETDRS chart, measured acuity in the left eye.

Visual acuity results were categorized as normal (20/40 or better visual acuity), below normal (worse than 20/40 to better than 20/200), poor (measurable acuity of 20/200 or worse), or blind/low vision (only the ability to detect the $2.2-\mathrm{cm}$ wide stripes on the Low Vision Teller acuity card at any distance and at any location in the visual field, light perception only, or no light perception). Acuity results in the normal and below normal categories were classified as favorable outcomes, and acuity results in the poor and blind/low vision categories were classified as unfavorable outcomes.

Monocular grating acuity was measured for all children using the Teller acuity card procedure. ${ }^{6,7}$ These results will be presented in future communications.

\section{Secondary Assessments}

Structural outcome was evaluated through a complete ophthalmological examination, including cycloplegic refraction following instillation of $1 \%$ cyclopentolate. When there was a medical contraindication to using $1 \%$ cyclopentolate, $0.5 \%$ cyclopentolate or $1 \%$ tropicamide was used. The examination was conducted by a study-certified ophthalmologist who was not formally masked to the eye's treatment assignment but was asked to refrain from seeking information and did not have access to visual acuity data until after completing the exam forms. An unfavorable retinal structural outcome was defined as follows: (1) a posterior retinal fold involving the macula, (2) a retinal detachment involving the macula, (3) retrolental tissue or mass obscuring the view of the posterior pole, and (4) a vitrectomy or scleral buckling procedure.

A questionnaire assessing the child's functional level was administered to the parents at the time of the 6-year evaluation by a trained individual (WeeFIM ${ }^{13}$ ). Children were tested for visual field extent and contrast sensitivity. ${ }^{14,15}$ Results of these examinations will be forthcoming in separate publications.

Data and Safety Monitoring Committee-A Data and Safety Monitoring Committee of biostatisticians, pediatric ophthalmologists, an ethicist, and a neonatologist, not directly involved with the study, met annually to review adverse events and monitor the progress of the study. The committee approved any protocol changes and monitored the performance of 
participating centers. Manuscripts for the study were also reviewed by the committee prior to submission for publication.

Statistical Methods-The statistical method that was developed for use in the CRYOROP Study ${ }^{16}$ was used for analysis of ETROP results. The method is an adaptation of the Mantel-Haenszel chi-square procedure for matched pairs data for children with symmetric disease that allows data from these children to be combined with data from children with asymmetric disease.

A further analysis was done comparing the full range of acuity using Wilcoxon nonparametric rank tests. For the symmetric eyes, an estimator of the treatment effect was computed using the Hodges-Lehmann estimator associated with Wilcoxon's signed rank test. ${ }^{17}$ Similarly, for the asymmetric eyes, an estimator of the treatment effect was computed using the Hodges-Lehmann estimator associated with the two sample Wilcoxon's rank sum test. A combined estimator of the treatment effect was computed by taking a weighted average of the two estimates of the treatment effect with weights proportional to the reciprocal of the variances of the estimators. In essence, this is equivalent to a meta analysis combining estimates of the treatment effect for symmetric eyes with asymmetric eyes. Also, an interaction test was done using a z-test comparing the difference in treatment effects for Type 1 eyes versus Type 2 eyes. The $\mathrm{z}$-value was computed by dividing the difference in the treatment effects by the square root of the sum of the variance in the two treatment effects.

\section{Results}

Figure 3B shows the protocol for all prethreshold eyes. Figure 3A shows the final disposition of the 401 ETROP study participants. At the final 6-year examination, 342 (92.4\%) of the surviving 370 children were examined; 271 children with symmetrical disease, and 71 children with asymmetrical disease. Eighteen children with moderate developmental delays could not perform the ETDRS test at the initial outcome assessment visit and were asked to return for subsequent testing. Thirteen children returned for retesting, of whom 10 were able to perform ETDRS testing. Their data are included in the primary outcome analysis. Of the 3 who could not provide ETDRS data, only one could be tested with the HOTV test. That child's data are not included in the visual acuity data analysis.

Table 1 presents the proportion of randomized eyes with unfavorable ETDRS acuity at 6 years of age. Overall, the data do not demonstrate a statistically significant benefit for early treatment, with $24.6 \%$ of early-treated high-risk prethreshold eyes and $29.0 \%$ of conventionally-managed eyes having unfavorable outcomes $(\mathrm{P}=0.15)$. Within-subject comparisons of the children with bilateral disease showed that there were 33 children with favorable outcomes in their early-treated eyes and unfavorable outcomes in their conventionally-managed eyes (discordant pairs), and twenty-four children had unfavorable outcomes in early-treated eyes and favorable outcomes in conventionally-managed eyes. This difference is not statistically significant $(\mathrm{P}=0.23)$. 
Table 2 provides the distribution of 6-year ETDRS acuity outcomes among randomized eyes by treatment assignment and visual acuity category. No data are shown for the 27 of the 307 early-treated eyes and the 23 of the 299 conventionally-managed eyes that could not be tested with the ETDRS charts. The ETDRS acuity data were analyzed comparing the two treatments using rank tests that control for whether a child had bilateral disease or asymmetric disease. The overall rank test for the shift in acuity distribution indicates a $\mathrm{P}$ value of 0.02 . This non-parametric approach shows a slightly higher number of eyes that are in the 20/60 or better categories for early treated eyes and at the same time slightly more eyes that are in the poorest category (blind/low vision) for conventionally-managed eyes (Figure 4).

Analysis of the ETDRS acuity data using Type 1 and Type 2 groupings as proposed in the 2003 ETROP results publication, is shown in Table 3 for eyes that were high risk based on the RM-ROP2 algorithm. ${ }^{9}$ Analysis using this clinical algorithm showed that Type 1 eyes had a $25.1 \%$ unfavorable outcome rate when treated early; while conventionally-managed Type 1 eyes had a $32.8 \%$ unfavorable outcome $(\mathrm{P}<0.001)$. By contrast, it is important to note that Type 2 eyes that were high-risk per RM-ROP2 showed no significant difference, with a slightly higher unfavorable outcome rate for the early-treated eyes of $23.6 \%$ versus $19.4 \%$ for conventionally-managed eyes $(\mathrm{P}=0.18)$.

Table 4 presents subgroups of ETDRS acuity outcome at 6 years for children with bilateral high-risk prethreshold ROP by ICROP category, RM-ROP2 Risk, and Type1/Type2 disease. The greatest benefit for early treatment was seen in eyes with Zone I, stage 3, with or without plus disease. The benefit of early treatment also increased with increasing risk, and was most pronounced in children with $\geq 45 \%$ risk for unfavorable outcome. When data were analyzed by Type 1 or Type 2 status, a significant benefit to early treatment for eyes with Type 1 disease is seen, but not for eyes with Type 2 disease.

For the secondary outcome, retinal structure, the difference in unfavorable outcomes for all high-risk prethreshold eyes was $8.9 \%$ for early treated eyes v. $15.2 \%$ for conventionally managed eyes (Table 5, $\mathrm{P}<0.001$ ). Data for children with symmetrical high-risk prethreshold disease showed that $10.0 \%$ of the early treated eyes v. $16.6 \%$ of the conventionally-managed eyes had unfavorable structural outcomes. Of children with symmetrical disease, 23 had favorable outcomes in early treated eyes and unfavorable outcomes in conventionallymanaged eyes. Six children had unfavorable outcomes in early treated and favorable outcomes in conventionally-managed eyes.

Table 6 presents subgroups of retinal structure outcomes at 6 years for children with bilateral high-risk prethreshold ROP by ICROP category, RM-ROP2 Risk and Type 1/Type 2 disease. As with visual acuity (Table 4), the greatest benefit for early treatment was seen in eyes with Zone I, stage 3, with or without plus disease, with a doubling of unfavorable outcomes in the conventionally managed eyes. There was also benefit for early treatment for Zone 2, stage 3, with plus disease. The benefit of early treatment also increased with increasing risk, and was most pronounced in children with $\geq 45 \%$ risk for unfavorable outcome. When data were analyzed by Type 1 or Type 2 status, a striking benefit to early treatment for eyes with Type 1 disease is seen, but not for eyes with Type 2 disease. 
Table 7 summarizes the ocular findings among early-treated high-risk prethreshold eyes versus conventionally managed high-risk prethreshold eyes that progressed and later underwent treatment at threshold ROP or underwent involution of ROP without requiring treatment. Ocular complication rates were similar in the two groups, though more conventionally-managed than early-treated eyes had unsteady fixation or retinal detachment. Cataract or aphakia was found in $4.9 \%$ of early-treated eyes and in $7.2 \%$ of conventionallymanaged eyes. With regard to mortality in the ETROP follow up cohort, 31 randomized children died before the 6-year exam, but none of the deaths was related to ophthalmology care.

\section{Discussion}

The ETROP Study was conducted on eyes that were high risk using the RM-ROP2 risk model. However, with a desire to have a clinical algorithm that could be conveniently applied, the evaluation of initial outcome data collected when study participants were 9 months corrected age included an analysis of results on the basis of standard ROP characteristics. ${ }^{8}$ The analysis identified eyes with characteristics indicating a benefit for early treatment (Type 1), and eyes that could be observed (Type 2), with treatment offered if the disease progresses to Type 1 . These divisions into Type 1 and Type 2 eyes were not preplanned as part of the original design in 1999, but came about in 2003, as a result of analysis of initial study outcome data. There was an obligation to follow these eyes according to this subdivision once the types had been developed and published.

As indicated in the present report, the importance of the difference between eyes with Type 1 versus Type 2 ROP is emphasized by the results of visual acuity assessment at age 6 years. Based on the predefined primary analysis, no statistically significant benefit at the $5 \%$ level was seen from early treatment compared to conventional management of high-risk prethreshold eyes when results were analyzed for all subjects who had high-risk prethreshold ROP, the criterion for entry into the study (risk 20.15 ). However, when the 6year visual acuity results were analyzed using the ETROP-developed clinical algorithms Type 1 and Type 2, a benefit was seen for Type 1 eyes $(\mathrm{P}=0.02)$ that were treated early, but not for early-treated Type 2 eyes (Table 3 ).

When one analyzes the ETDRS data as continuous rather than categorical (favorable vs unfavorable) data, the results for Type 1 and Type 2 clearly show different outcomes (Type 1 eyes, $\mathrm{P}<0.001$; Type 2 eyes $\mathrm{P}=0.18$ ), and analysis of an interaction effect showed that differences between treatment for Type 1 eyes versus Type 2 eyes were highly significant $(\mathrm{P}=0.006)$. Results presented in 2003 calling for watchful waiting for Type 2 eyes are even more important given the ETDRS acuity results at age 6 years, because data on structural outcome at 6 months corrected age indicated that $77.3 \%$ of low and high-risk Type 2 eyes regress; whereas, $31.5 \%$ of Type 1 eyes (whether low- or high-risk prethreshold eyes) regress. ${ }^{8}$

Retinal structural outcome continues to show a benefit from early treatment. This benefit was noted at 6 and 9 months corrected age and at 2 years postnatal age ${ }^{10}$ and has persisted to the 6-year outcome examination. Structural benefit exceeds visual acuity outcome benefit in 
the 6-year examination, just as it did at the 9-month examination, ${ }^{8}$ and as it did in the CRYO-ROP Study. ${ }^{4}$ There are a number of reasons for this, including the possibility that ROP per se somehow affects visual acuity, or that central nervous system changes related to preterm birth are partially responsible for reduction in visual acuity. ${ }^{18}$ While immaturity of the visual system at 9 months of age could have accounted for this discrepancy, by 6 years the visual system is nearly mature.

The findings of the present report are strengthened because of the high follow up rate (over $92 \%$ ), certification and training of the ophthalmologists who performed the examinations on which characterization of ROP and the randomization of study participants were based, the certification and training of the ophthalmologists who performed study outcome examinations, and the training, certification and masking of the visual acuity testers. The potential diagnostic uncertainty of "plus" disease, a characteristic that carries considerable importance in distinguishing Type 1 from Type 2 prethreshold ROP, may represent a limitation. To minimize this potential uncertainty, the Study used confirming examinations by masked, certified examiners prior to randomization, the group of investigators held regular meetings to review criteria for plus disease, and site visits to examine infants at each of the centers were used to calibrate study-certified ophthalmologists.

The CRYO-ROP Study showed a benefit for treatment at threshold retinopathy of prematurity (Figure 1). However, visual acuity outcome measures indicated that many children still had acuity of 20/200 or worse. In the 10-year follow up examination, the rate of unfavorable visual acuity outcome (20/200 or worse) after cryotherapy was $44.4 \%$ for treated eyes and $62.1 \%$ for control (untreated) eyes. ${ }^{19}$ At the 15 -year follow-up examination, the distribution of unfavorable visual acuity outcomes was $44.7 \%$ in treated eyes v. $64.3 \%$ in control eyes. ${ }^{20}$ One of the motivations for testing whether early treatment of eyes with ROP of near-threshold severity was to learn whether visual acuity results would improve with this management approach.

In the ETROP Study, when children reached 6 years of age, $24.7 \%$ of eyes treated at highrisk prethreshold ROP showed visual acuity of 20/200 or worse v. $29.0 \%$ of eyes conventionally managed. When Type 1 eyes were considered, the difference between early treatment and conventional management was 25.1 v. $32.8 \%$. Improvement was noted for eyes with Type 1 ROP only, with Type 2 eyes showing no benefit. Two-thirds of early treated eyes still showed visual acuity worse than 20/40. Comparisons to data from the CRYO-ROP Study cannot be made because the cohorts of children are very different. In the CRYO-ROP Study, all infants with birth weight $<1251$ grams were eligible for randomization if threshold disease developed. In the ETROP Study, infants had to be $<1251$ grams, have prethreshold ROP, and have a risk for blindness $\geq 15 \%$ to be eligible for randomization.

Is there any evidence that treatment for Type 2 ROP could be deleterious to the eye or to the patient? In the ETROP Study, $41.3 \%$ of randomized eyes had Zone I disease. While possible reasons for this high percentage have been discussed ${ }^{8}$, these eyes received an extensive amount of peripheral retinal ablation, and are at risk for visual field loss. A future manuscript will present and discuss the visual field findings. Data from visual acuity 
findings indicate that early treatment of eyes at the time of identification of prethreshold disease with Type 2 characteristics is of no benefit (23.6\% unfavorable acuity outcome with early treatment v. $19.4 \%$ unfavorable with conventional management) Furthermore, there is no benefit from early treatment for Type 2 eyes on analysis of structural outcome (Table 6). Additionally, in the previous publication ${ }^{8}$ we noted that $52 \%$ of high-risk Type 2 eyes regressed without requiring treatment. Given the possible risks, such as risk for cataract ${ }^{10}$ and increased systemic risk for apnea and bradycardia, ${ }^{8}$ it would seem prudent to exercise restraint and clinical judgment when deciding whether to operate on Type 2 eyes unless they show signs of further progression.

In conclusion, the final visual acuity examination at 6 years of age in children enrolled in the Early Treatment for Retinopathy of Prematurity Study shows a lasting benefit for early treatment of some eyes with ROP. However, the benefit is present only for eyes with Type 1 disease as defined in this study. Visual acuity is improved with early treatment, but nevertheless, $65.4 \%$ of eyes receiving early treatment develop visual acuity worse than 20/40. Whether this result is due to retinal, cortical, or both factors remains to be determined, but clearly prevention of ROP now assumes an even higher priority since early treatment is beneficial for some eyes but often does not result in normal development of visual acuity.

\section{Acknowledgments}

Supported by Cooperative Agreements (5U10 EY12471 and 5U10 EY12472) with the National Eye Institute of the National Institutes of Health, U.S. Department of Health and Human Services, Bethesda, Maryland.

\section{References}

1. Cryotherapy for Retinopathy of Prematurity Cooperative Group. Multicenter trial of cryotherapy for retinopathy of prematurity: preliminary results. Pediatrics. May; 1988 81(5):697-706. [PubMed: 2895910]

2. Cryotherapy for Retinopathy of Prematurity Cooperative Group. Multicenter trial of cryotherapy for retinopathy of prematurity. Preliminary results. Arch Ophthalmol. Apr; 1988 106(4):471-479. [PubMed: 2895630]

3. The Committee for the Classification of Retinopathy of Prematurity. An international classification of retinopathy of prematurity. Arch Ophthalmol. Aug; 1984 102(8):1130-1134. [PubMed: 6547831]

4. Cryotherapy for Retinopathy of Prematurity Cooperative Group. Multicenter trial of cryotherapy for retinopathy of prematurity. One-year outcome--structure and function. Arch Ophthalmol. Oct; 1990 108(10):1408-1416. [PubMed: 2222274]

5. Good WV, Hardy RJ. The multicenter study of Early Treatment for Retinopathy of Prematurity (ETROP). Ophthalmology. Jun; 2001 108(6):1013-1014. [PubMed: 11382621]

6. Dobson V, Quinn GE, Biglan AW, Tung B, Flynn JT, Palmer EA. Acuity card assessment of visual function in the cryotherapy for retinopathy of prematurity trial. Invest Ophthalmol Vis Sci. Sep; 1990 31(9):1702-1708. [PubMed: 2211019]

7. Teller DY, McDonald MA, Preston K, Sebris SL, Dobson V. Assessment of visual acuity in infants and children: the acuity card procedure. Dev Med Child Neurol. Dec; 1986 28(6):779-789. [PubMed: 3817317]

8. Early Treatment For Retinopathy Of Prematurity Cooperative Group. Revised indications for the treatment of retinopathy of prematurity: results of the early treatment for retinopathy of prematurity randomized trial. Arch Ophthalmol. Dec; 2003 121(12):1684-1694. [PubMed: 14662586]

9. Hardy RJ, Palmer EA, Dobson V, et al. Risk analysis of prethreshold retinopathy of prematurity. Arch Ophthalmol. Dec; 2003 121(12):1697-1701. [PubMed: 14662587] 
10. Good WV. The Early Treatment for Retinopathy Of Prematurity Study: structural findings at age 2 years. Br J Ophthalmol. Nov; 2006 90(11):1378-1382. [PubMed: 16914473]

11. Hardy RJ, Good WV, Dobson V, et al. Multicenter trial of early treatment for retinopathy of prematurity: study design. Control Clin Trials. Jun; 2004 25(3):311-325. [PubMed: 15157731]

12. Ferris FL 3rd, Kassoff A, Bresnick GH, Bailey I. New visual acuity charts for clinical research. Am J Ophthalmol. Jul; 1982 94(1):91-96. [PubMed: 7091289]

13. Msall ME, Phelps DL, DiGaudio KM, Dobson V, Tung B, McClead RE, Quinn GE, Reynolds JD, Hardy RJ, Palmer EA. Severity of neonatal retinopathy of prematurity is predictive of neurodevelopmental functional outcome at age 5.5 years. Pediatrics. Nov; 2000 106(5):998-1005. [PubMed: 11061766]

14. Quinn GE, Dobson V, Hardy RJ, Tung B, Phelps DL, Palmer EA. Visual fields measured with double-arc perimetry in eyes with threshold retinopathy of prematurity from the cryotherapy for retinopathy of prematurity trial. Sep; 1996 103(9):1432-1437.

15. Cryotherapy for Retinopathy of Prematurity Cooperative Group. Contrast sensitivity at age 10 years in children who had threshold retinopathy of prematurity. Arch Ophthalmol. Aug; 2001 119(8):1129-1133. [PubMed: 11483078]

16. Hardy, RJ.; Davis, BR. 1989 Proceedings of Biopharmaceutical Section. Alexandria, VA: American Statistical Association; 1989. The Design Analysis, and Monitoring of an Ophthalmological Clinical Trial: American Statistical Association; p. 248-253.

17. Hollander, M.; Wolfe, DA. Wiley Series in Probability and Statistics. 2nd. John Wiley \& Sons; NJ: 1999. Nonparametric Statistical Methods.

18. Siatkowski RM, Dobson V, Quinn GE, Summers CG, Palmer EA, Tung B. Severe visual impairment in children with mild or moderate retinal residua following regressed threshold retinopathy of prematurity. J AAPOS. Apr; 2007 11(2):148-152. [PubMed: 17416324]

19. Cryotherapy for Retinopathy of Prematurity Cooperative Group. Ophthalmological outcomes at 10 years. Arch Ophthalmol. Aug; 2001 119(8):1110-1118. [PubMed: 11483076]

20. Cryotherapy for Retinopathy of Prematurity Cooperative Group. 15-year outcomes following threshold retinopathy of prematurity: final results from the multicenter trial of cryotherapy for retinopathy of prematurity. Arch Ophthalmol. Mar; 2005 123(3):311-318. [PubMed: 15767472] 


\section{Threshold ROP (CRYO-ROP):}

Zone I or II, with 5 contiguous or 8 cumulative clock hours of stage 3 , and plus disease

\section{Prethreshold ROP (CRYO-ROP):}

Zone I or Zone II stage 3, or Zone II stage 2 with plus disease

\section{High-Risk Prethreshold:}

RM-ROP2 risk $^{9}$ greater than or equal to 0.15

\section{Low-Risk Prethreshold:}

RM-ROP2 risk $^{9}$ less than 0.15

Type 1 (ETROP):

Zone I, any stage ROP with plus disease (plus is 2 or more quadrants in the ETROP Study)

Zone I, stage 3 ROP with or without plus disease

Zone II, stage 2 or 3 ROP with plus disease

\section{Type 2 (ETROP):}

Zone I, stage 1 or 2 ROP without plus disease

Zone II, stage 3 ROP without plus disease

Figure 1. Research definitions of ROP categories 


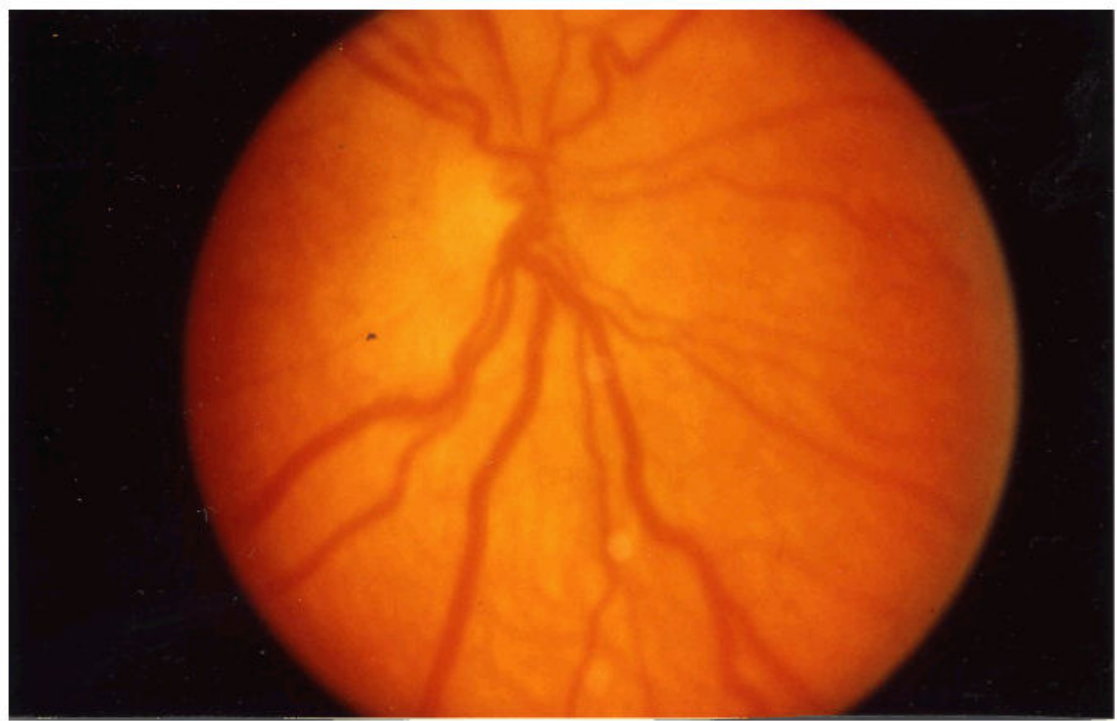

Figure 2.

Standard photograph of plus disease

The ETROP Study used this standard photograph for plus disease. At least 2 quadrants of dilation and tortuosity were required for the diagnosis of plus. 


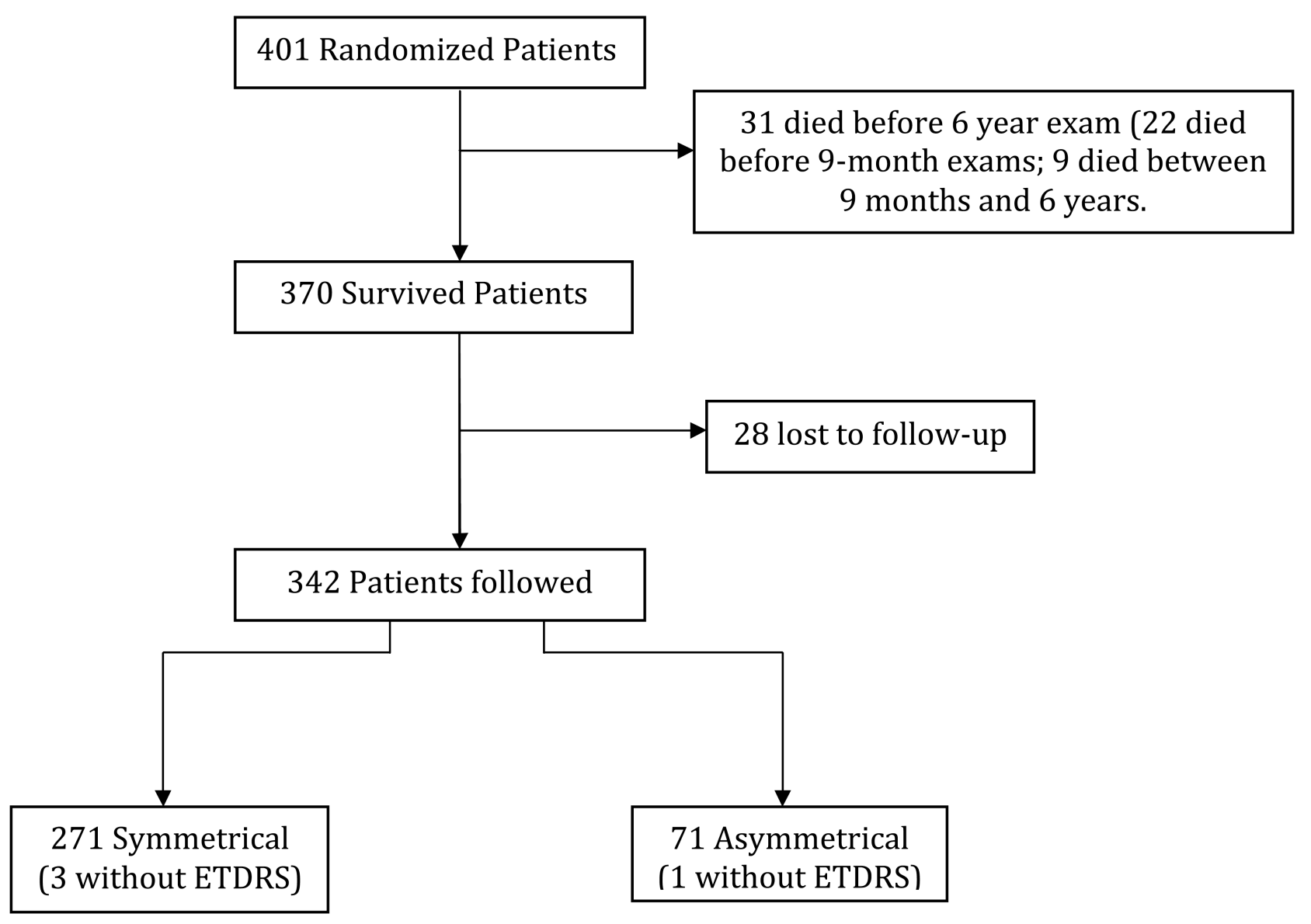

Figure 3A. Algorithm (flow chart) for randomized infants 


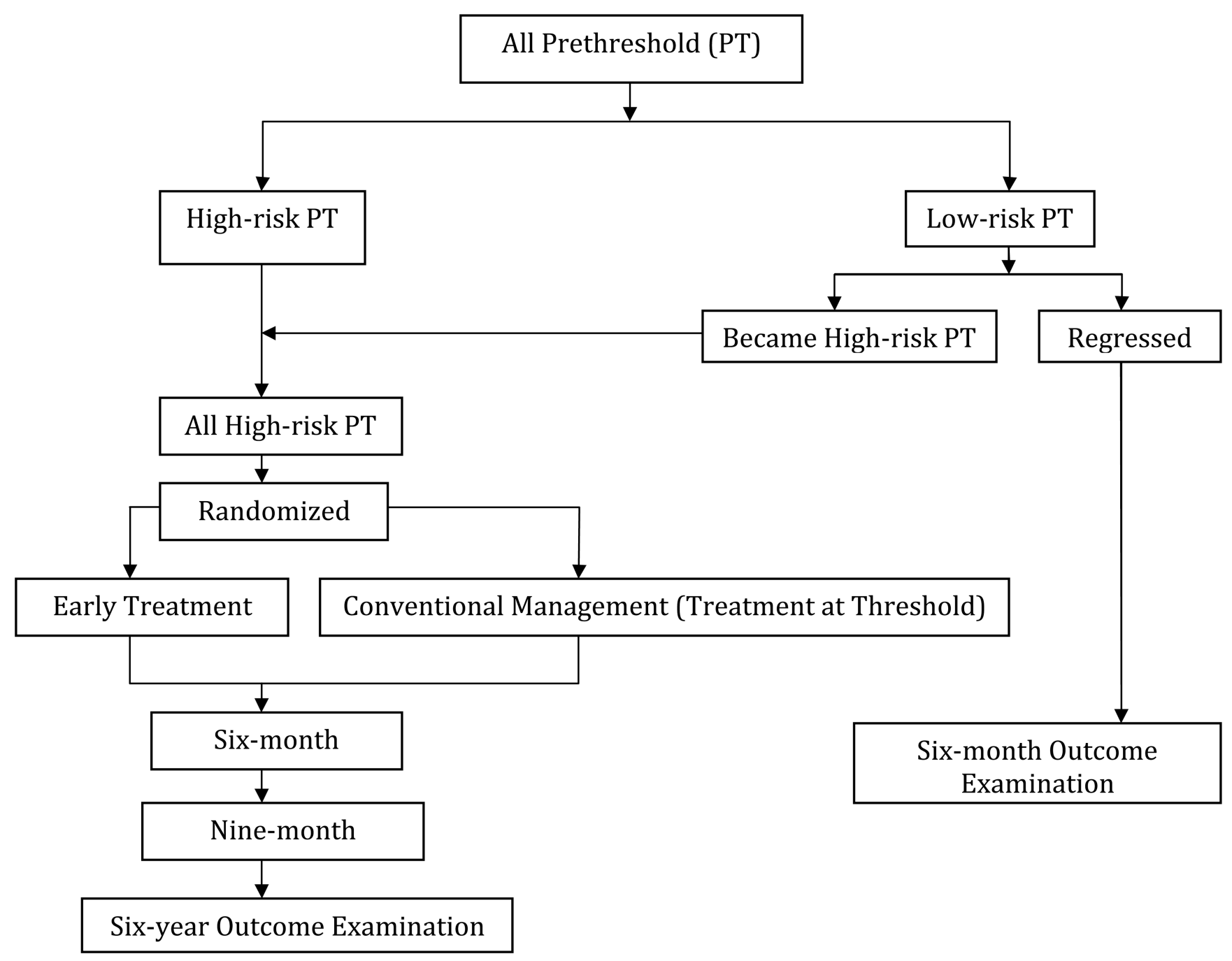

Figure 3B. Algorithm for all prethreshold eyes 


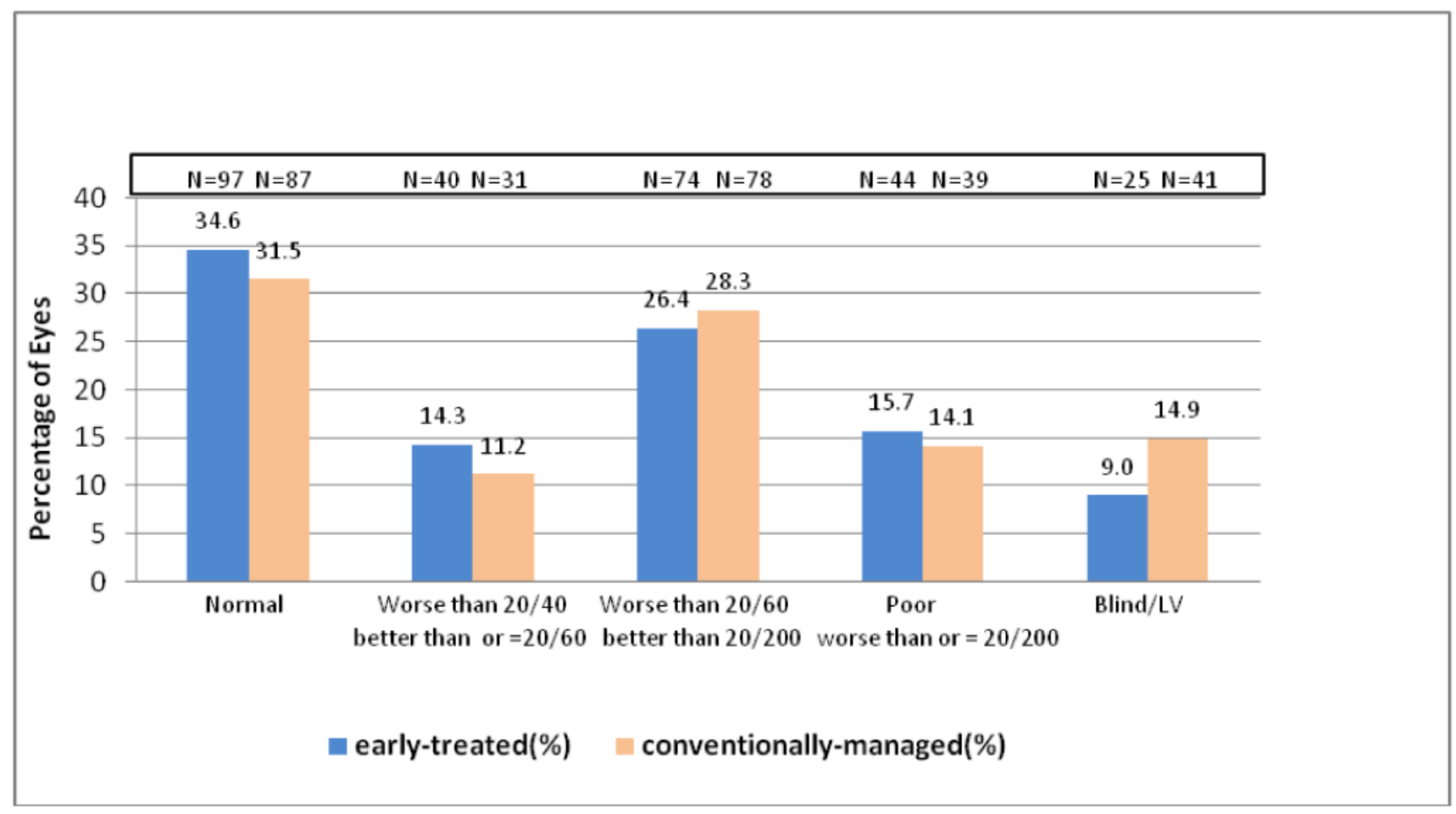

Figure 4. Distribution of Six-year ETDRS Acuity Outcomes Among Randomized Eyes, by Treatment Assignment 
Table 2

Distribution of Six-Year ETDRS Acuity Outcomes Among Randomized Eyes by Treatment Assignment.

\begin{tabular}{lllll}
\hline & \multicolumn{2}{l}{ Eyes Treated at High-Risk Prethreshold } & \multicolumn{2}{l}{ Conventionally Managed Eyes } \\
\hline Favorable Outcome & $\mathbf{N}$ & $\mathbf{( \% )}$ & $\mathbf{N}$ & $\mathbf{( \% )}$ \\
\hline Normal (20/40 or better) & 97 & $(34.6)$ & 87 & $(31.5)$ \\
Worse than 20/40, better than or equal to 20/60 & 40 & $(14.3)$ & 31 & $(11.2)$ \\
Worse than 20/60, better than 20/200 & 74 & $(26.4)$ & 78 & $(28.3)$ \\
\hline Unfavorable Outcome & & & 39 & $(14.1)$ \\
\hline Poor (worse or equal to 20/200) & 44 & $(15.7)$ & 41 & $(14.9)$ \\
Blind/Low Vision (NLP, LP, LV card) & 25 & $(9.0)$ & 23 & \\
\hline Cannot be done due to Neurodevelopmental delay & 27 & & 299 & \\
\hline Total & 307 & & & \\
\hline
\end{tabular}

NLP: No light perception

LP: Light perception only

LV card: Low vision card only 
Page 19

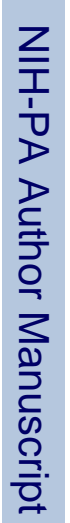

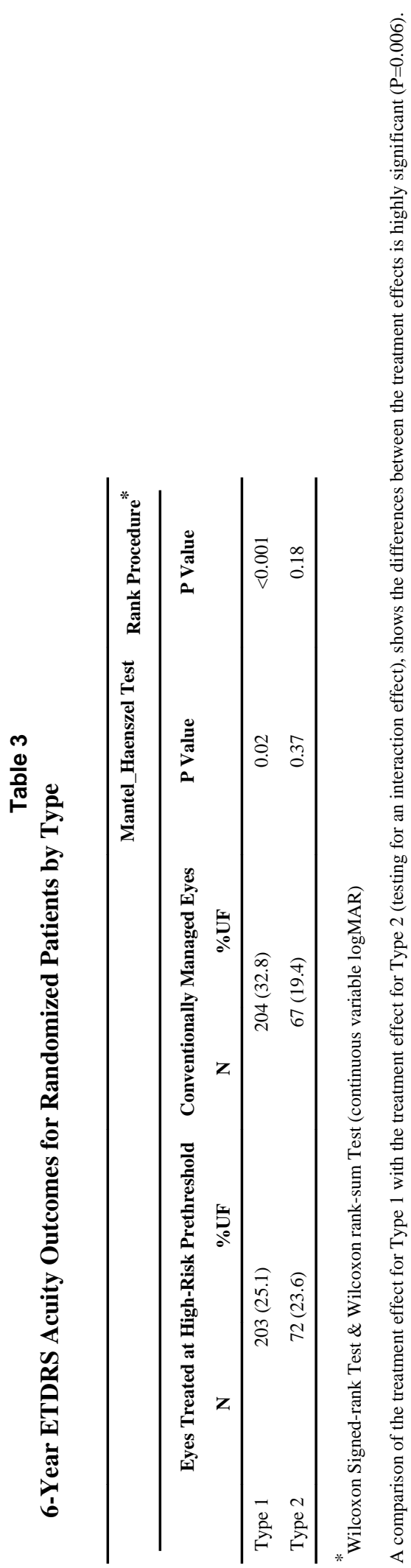

Arch Ophthalmol. Author manuscript; available in PMC 2014 September 12. 
Table 4

ETDRS Acuity Outcome at 6-Year Examination for Children with Bilateral High-Risk Prethreshold Retinopathy of Prematurity by ICROP Category and RM-ROP2 Risk ${ }^{* * * *}$

\begin{tabular}{lcrrr}
\hline Both Eyes & Eyes Treated at High-Risk Prethreshold & Conventionally Managed Eyes & Discordant Pairs \\
& & & A $^{*}$ & B $^{* * *}$ \\
\hline & ICROP Classification & & \\
Z1 S3 +/- & $23(30.4)$ & $23(65.2)$ & 9 & 1 \\
Z1 S1/2+ & $7(57.1)$ & $7(57.1)$ & 1 & 1 \\
Z1 S1/2- & $61(26.2)$ & $61(21.3)$ & 6 & 9 \\
Z2 S3+ & $97(24.7)$ & $96(27.1)$ & 10 & 7 \\
Z2 S3 - & $3(0.0)$ & $3(0.0)$ & 0 & 0 \\
Z2 S2 + & $30(23.3)$ & $30(30.0)$ & 4 & 2 \\
\hline & RM-ROP2 Risk & $91(19.8)$ & 10 & 10 \\
$0.15-<0.30$ & $91(19.8)$ & $69(30.4)$ & 12 & 8 \\
$0.30-<0.45$ & $69(24.6)$ & $67(47.8)$ & 10 & 2 \\
$>0.45$ & $67(35.8)$ & & & \\
\hline & TYPE 1/TYPE 2 & $178(34.8)$ & 27 & 14 \\
Type 1 & $178(27.5)$ & $64(20.3)$ & 6 & 9 \\
Type 2 & $64(25.0)$ & &
\end{tabular}

* For group A, early-treated eyes had a favorable outcome, and conventionally managed eyes had an unfavorable outcome.

** For group B, early-treated eyes had an unfavorable outcome, and conventionally managed eyes had a favorable outcome. $* * *$

Data are presented as number (percent unfavorable) unless otherwise indicated. 
Table 5

6-Year Structural Outcome for Randomized Patients*

\begin{tabular}{|c|c|c|c|c|}
\hline & Eyes Treated at High-Risk Prethreshold & Conventionally Managed Eyes & $\mathbf{X}^{2}$ & P Value \\
\hline Bilateral & $269^{* *}(10.0)$ & $271(16.6)$ & 9.97 \# & 0.002 \\
\hline Asymmetric & $36^{\wedge}(0.0)$ & $32(3.1)$ & 1.14 & 0.29 \\
\hline Total & $305(8.9)$ & $303(15.2)$ & 10.87 & $<0.001$ \\
\hline \multicolumn{5}{|c|}{ Data are presented as number (percent unfavorable) unless otherwise indicated. } \\
\hline \multicolumn{5}{|c|}{ *** ${ }^{*}$ Less than 271 because of inability to determine the structural outcome. } \\
\hline \multicolumn{5}{|c|}{ Less than 39 because of inability to determine the structural outcome. } \\
\hline
\end{tabular}


Table 6

Structural Outcome at 6-Year Examination for Children with Bilateral High-Risk Prethreshold Retinopathy of Prematurity by ICROP Category and RM-ROP2 Risk****

\begin{tabular}{|c|c|c|c|c|}
\hline & \multirow{2}{*}{ Eyes Treated at High-Risk Prethreshold } & \multirow{2}{*}{ Conventionally Managed Eyes } & \multicolumn{2}{|c|}{ Discordant Pairs } \\
\hline & & & $A^{*}$ & $\mathbf{B}^{* *}$ \\
\hline \multicolumn{5}{|c|}{ ICROP Classification } \\
\hline $\mathrm{Z} 1 \mathrm{~S} 3+/-$ & $23(21.7)$ & $24(58.3)$ & 8 & 0 \\
\hline $\mathrm{Z} 1 \mathrm{~S} 1 / 2+$ & $9(22.2)$ & $9(22.2)$ & 0 & 0 \\
\hline $\mathrm{Z} 1 \mathrm{~S} 1 / 2$ - & $67(4.5)$ & $67(6.0)$ & 3 & 2 \\
\hline $\mathrm{Z} 2 \mathrm{~S} 3+$ & $103(7.8)$ & $104(12.5)$ & 8 & 3 \\
\hline Z2 S3 - & $3(0.0)$ & $3(0.0)$ & 0 & 0 \\
\hline $\mathrm{Z} 2 \mathrm{~S} 2+$ & $33(21.2)$ & $33(21.2)$ & 1 & 1 \\
\hline \multicolumn{5}{|c|}{ RM-ROP2 Risk } \\
\hline $0.15-<0.30$ & $101(7.9)$ & $101(5.9)$ & 2 & 4 \\
\hline $0.30-<0.45$ & $70(8.6)$ & $71(16.9)$ & 6 & 0 \\
\hline$>0.45$ & $73(16.4)$ & $74(32.4)$ & 13 & 2 \\
\hline \multicolumn{5}{|c|}{ TYPE 1/TYPE 2 (two eyes may have different ICROP code) } \\
\hline Type 1 & $191(12.6)$ & $193(20.2)$ & 18 & 4 \\
\hline Type 2 & $70(4.3)$ & $70(5.7)$ & 3 & 2 \\
\hline
\end{tabular}


Page 24

Arch Ophthalmol. Author manuscript; available in PMC 2014 September 12. 